IZA DP No. 9819

Old-Age Employment and Hours of Work Trends: Empirical Analysis for Four European Countries

Arjeta Aliaj

Xavier Flawinne

Alain Jousten

Sergio Perelman

Lin Shi

March 2016 


\title{
Old-Age Employment and Hours of Work Trends: Empirical Analysis for Four European Countries
}

\author{
Arjeta Aliaj \\ HEC, University of Liege \\ Xavier Flawinne \\ HEC, University of Liege
}

\author{
Sergio Perelman \\ HEC, University of Liege
}

Lin Shi

HEC, University of Liege

\author{
Alain Jousten \\ HEC, University of Liege and IZA
}

\author{
Discussion Paper No. 9819 \\ March 2016
}

\author{
IZA \\ P.O. Box 7240 \\ 53072 Bonn \\ Germany \\ Phone: +49-228-3894-0 \\ Fax: +49-228-3894-180 \\ E-mail: iza@iza.org
}

\begin{abstract}
Any opinions expressed here are those of the author(s) and not those of IZA. Research published in this series may include views on policy, but the institute itself takes no institutional policy positions. The IZA research network is committed to the IZA Guiding Principles of Research Integrity.

The Institute for the Study of Labor (IZA) in Bonn is a local and virtual international research center and a place of communication between science, politics and business. IZA is an independent nonprofit organization supported by Deutsche Post Foundation. The center is associated with the University of Bonn and offers a stimulating research environment through its international network, workshops and conferences, data service, project support, research visits and doctoral program. IZA engages in (i) original and internationally competitive research in all fields of labor economics, (ii) development of policy concepts, and (iii) dissemination of research results and concepts to the interested public.
\end{abstract}

IZA Discussion Papers often represent preliminary work and are circulated to encourage discussion. Citation of such a paper should account for its provisional character. A revised version may be available directly from the author. 


\section{ABSTRACT}

\section{Old-Age Employment and Hours of Work Trends: Empirical Analysis for Four European Countries*}

For the last two decades, the increase of employment among cohorts of individuals aged 50+ has been a policy objective on the European employment agenda. The present paper takes stock of the situation as observed in Belgium over the time period 1997-2011. First, we provide analysis on the evolution of older workers' employment in Belgium and its neighboring countries Germany, France and the Netherlands using the EU Labour Force Survey. Second, we characterize the different employment and hours of work patterns for different age sub-groups (50-54, 55-59, 60-64) and provide evidence on their respective evolution. The results show that employment rates among older workers started to catch-up with employment rates of younger cohorts as of 2001, and with more acuity after 2006 . This effect dominates the observed negative effect on hours of work and hence leads to an increase in total hours of work of the cohort - net of any purely demographic effects.

JEL Classification: J08, J21, J26

Keywords: retirement, employment, hours of work

Corresponding author:

Alain Jousten

HEC Ecole de Gestion

Université de Liège

Boulevard du Rectorat 7, Bât. B31

4000 Liege

Belgium

E-mail: ajousten@ulg.ac.be

\footnotetext{
* We are grateful to Eric Bonsang as well as seminar participants at IAB (Nürnberg) and Belspo for their helpful comments and suggestions. The authors acknowledge financial support from the Belspo project EMPOV (TA/00/45). This paper uses data from the European Union Labour Force Survey (Eurostat, European Union). Eurostat has no responsibility for the results and conclusions which are the authors' only.
} 


\section{Introduction}

Most European Union countries face the challenge of an aging population and the associated issue of short and long-term sustainability of pay-as-you-go public pension schemes - Belgium is no exception to the rule. Several factors are at stake. Some are demographic: in 2010 the first babyboomers reached the age of retirement, with an average life expectancy 10 years higher than workers who retired in 1980; the baby-boomers cohort is replaced in the labor market by a substantially smaller baby-bust cohort born in the early 90's. Some others are often associated with social norms and regulations - though demography also plays its role: e.g. an increased reliance on part-time work before (and after) the full retirement age, or the long-run increase in female labor force participation among all age groups.

The age group 50+ has benefited from a special attention on behalf of policy makers - partially nodoubt also motivated by the rather low observed employment rates (ER) in numerous European countries. Increased employment is associated with a triple benefit: First, keeping older workers in employment often means both more people paying social security contributions and less people collecting retirement benefits. Second, active ageing is considered beneficial for health and recommended by international institutions like WHO (2002) and the European Commission (2012). ${ }^{1}$ And third, more specifically for women, employment can help prevent the risk of old-age poverty associated with shorter and more interrupted earnings histories.

The Open Method of Coordination (OMC) provided a first formalization of employment objectives for the age group in focus. The OMC was introduced by the European Council (2000) as part of the Lisbon Strategy and included the improvement of women's employment to a rate of $60 \%$ or more as a goal for member countries in 2010. One year later, the European Council (2001) established an extended list of indicators in the field of social inclusion and social protection (Laeken indicators) and new OMC goals. One of them - a pension sustainability indicator - targeted the increase of the ER of the 55 to 64 years old to $50 \%$ or more. ${ }^{2}$

In some way, the OMC adopted in 2001 announced a change of paradigm. Even if the arguments in favor of increasing employment among older workers appear today as self-evident, this was not always the case. On the contrary, from the middle of the seventies to the middle of the 90's, most EU countries introduced social protection reforms which allowed older workers to leave the labor market before the full or legal retirement age, in some cases as early as age $50 .^{3}$ The generosity of early retirement and pension benefits played in most cases the role of incentives in favor of early exit, in the face of a large perceived residual capacity to work. ${ }^{4}$ This was documented in Gruber and Wise (2004) and Wise (2016) for several countries, including Belgium and its immediate neighbors France, Germany and the Netherlands.

\footnotetext{
${ }^{1}$ Active ageing means keeping professional or non-professional activities. Moreover, in a recent study, Bonsang et al (2012), found a positive correlation between early retirement and cognitive decline.

${ }^{2}$ See European Council $(2000,2001)$

${ }^{3}$ Lefebvre (2013) analyses the complex relationships, between workers, firms and governments, which have conditioned the implementation of early retirement schemes during this period.

${ }^{4} \mathrm{~A}$ key issue in pension computations is how pension benefits are actuarially adapted, or not, to take into account the effective age of retirement and the evolution of life expectations.
} 
Higher ERs among older workers thus became a new explicit and central target of public policy, among others to keep pension schemes sustainable and to avoid labor supply shortages. ${ }^{5}$ On the specific measures, the $\mathrm{OMC}$ remained non-prescriptive and flexible: member states kept a total freedom as to the precise tools they selected for implementation to achieve the "macro-level" OMC objectives. Even in terms of its targets, the OMC remained rather unconstraining as witnessed by the progressive elimination of any age-cohort specific targets from later EU initiatives.

The large degree of flexibility entrusted upon member states for their policy tools also reflects on our general approach in this paper. We take a descriptive approach of aggregate indicators of labor market outcomes over time and across countries using data from the EU Labour Force Survey (EULFS). We focus on Belgium and its immediate neighbors, Germany, France and the Netherlands as countries with a comparable economic development but different labor market outcomes. We comprehensively assess the global trends in ERs, rather than taking an approach of trying to identify the effect (if any) of individual policy measures - or for this matter changes in (hard-to-identify) implementing regulations or information. ${ }^{6}$ The approach is all the more relevant as general policy measures (e.g., absence of age discrimination) further had indissociable effects on labor market outcomes.

We also provide analysis of indicators of hours of work - an indicator beyond the scope of most European and Belgian policy-makers - complementing the analysis based on well-trodden employment indicators. Questions that can be answered with such indicators are: is part-time employment the price paid to reach higher ERs? ; did the financial crisis affect hours of work differently than employment among older workers? ; did some socio-economic groups react differently in employment and in hours of work than others? For this purpose, we estimate a Heckman (1979) selection model in which the dependent variable is the usual hours of work and among the explanatory variables, other than age, education and country of birth, the years of job tenure on the current job. As for the rate of employment, we test econometrically the differences across periods by country, both for women and men.

The paper is organized in 6 sections. In section 2 we provide some brief background statistics on labor market trends for the elderly. Section 3 describes our empirical approach and presents the detailed results of probit model estimations with employment as the dependent variable. Section 4 extends the reflection beyond ERs by focusing on the effects of socio-economic factors on hours of work. We present econometric estimates relating to usual hours of work at the level of the individual. We also provide micro-simulation results regarding the combined effect of ER and hours of work changes on total work hours - carefully distinguishing them from purely demographic effects. Section 5 contains the main conclusions of this paper.

\footnotetext{
${ }^{5}$ Here, we make the assumption that younger and older workers are complementary, not substitutes, in the labor market. For a test, and the rejection, of the fixed lump of labor hypothesis in several OECD countries see Gruber and Wise (2010).

${ }^{6}$ See, for example, the better disclosure on the positive effects of activity on health outcomes such as promoted by European Commission (1999).
} 


\section{Labor market trends}

Figure 1 shows the evolution of ERs separately for men and women in the 50 to 64 years old cohorts. The series, computed using EU-LFS data, are complete for Belgium and France (1983 to 2011) but incomplete for the Netherlands (starting on a yearly basis in 1987) and for Germany (starting in 2001). We learn that ERs followed a rather similar path across these countries: up to the middle of the 1990s, a relatively stable or slightly increasing path among women (e.g. the Netherlands), and a decreasing one among men. From the mid-1990s on, there is a quick recovery, particularly among women but also among men (e.g. Germany and the Netherlands). A catching-up process is at work between female and male ERs at older ages. Figure 1 also reveals major differences across countries, with Belgium being the country with the lowest overall ER in the sample of countries: while Belgium and France both have rather low male employment, Belgium also has distinctly lower female employment.

\section{INSERT FIGURE 1}

Figure 2 illustrates the evolution of the average hours of work among men and women aged 50 to 64 years old. As expected, women work less hours per week than men in the four countries and the gap is particularly large in the case of the Netherlands, where women on average work less than 25 hours/week.

\section{INSERT FIGURE 2}

We also distinguish several age-groups, to identify the differential impact of events on these cohorts. We compare the evolution of male and female employment with counter-factual situations: on the one hand, with the evolution of ERs among younger cohorts, mostly the 45 to 49 years old ${ }^{7}$; on the other hand, with the evolution of ERs observed for women and men in the same age cohorts but living in neighboring countries. Figure 3 illustrates the evolution of ERs, for four age categories - 4549, 50-54, 55-59 and 60-64 years old - over the period 1997-2011 - with vertical lines marking the three sub-periods of study 1997-2001, 2002-2006 and 2007-2011. ${ }^{8}$ First of all, we observe that even if in all cases ER grew without discontinuity after 2001 among the 55-59 and the 60-64 years old, at the end of the period important gaps subsist with respect to the younger cohorts. Second, in most cases the gap between the 50-54 and the $45-49$ years old is small, with the exception of women in Belgium and, to a lesser extent, women in the Netherlands pointing at different activity and retirement patterns for women in these countries. Third, ER increases much stronger among the 6064 years old of both sexes in Germany and the Netherlands than in Belgium and France. ${ }^{9}$

\section{INSERT FIGURE 3}

\footnotetext{
${ }^{7}$ To evaluate the relative labor market performance of the population aged 55-64, we use the age group 45-49 as a comparator rather than the group 50-54 - as the latter is in some cases already more heavily affected by the availability of early retirement programs.

${ }^{8}$ A finer breakdown of age is not possible as in EU-LFS data age is only available in 5-year brackets.

${ }^{9}$ Steiner (2015) observed the same evolution in 60-64 years old ER in Germany using the Socioeconomic Panel (SOEP) data.
} 


\section{Employment estimations}

\section{Empirical approach}

We are interested in identifying differences in employment controlling at the same time for differences across age categories, educational attainment, country of birth and marital status. For this purpose, we use the representative EU-LFS micro-data to estimate probabilistic probit models in which the dependent variable is to be employed or not, and as explanatory variables binary variables representing age cohorts, educational attainment, country of birth and marital status.

We distinguish three 5-year sub-periods: 1997-2001, 2002-2006 and 2007-2011. All three correspond to distinct events in the overall policy and economic environment. 2002-2006 versus 1997-2001 corresponds to a comparison of the aftermath and the period immediately leading towards the "paradigm shift" around the Lisbon and Laeken indicators. 2007-2011 corresponds to a period right after the onset of the worldwide financial crisis, hence representing a potentially large shock to the labor markets. We want to identify differences across periods for the four countries; therefore the same analysis is done by country and separately for women and men.

In order to control for individual characteristics, three other dimensions are included in the analysis: educational attainment, country of birth and marital status. Proceeding in this way, we can identify to what extent the reforms undertaken were favorable to particular categories of workers, like the low skilled and foreigners. Tables 1 and 2 present ER for two of these dimensions, education and country of birth, over the analyzed period for the population aged 45-64.

In both tables and for most categories, the ER follows over time the general trend observed in previous figures, particularly among women. However, looking in details at the numbers reported in Table 1, it is interesting to note that among high educated men and women ER differences are relatively small, not higher than 12.0 percentage points ( $80.6 \%$ vs. $69.2 \%$ for Belgium in 2007-2011), while the gap is twice as high for people with low education, e.g. $70.1 \%$ vs. $44.5 \%$ for the Netherlands and $52.7 \%$ vs. $32.7 \%$ for Belgium in 2007-2011.

\section{INSERT TABLE 1}

In Table 2, as expected, ER are lower among people born abroad but the gap varies from near 2.2 to 15.0 percentage points when comparing men's ER in 1997-2001 in the Netherlands, with France in 2007-2011. Moreover, there is not a clear common pattern in the evolution of ER by country of birth. In some cases, specifically in Belgium and the Netherlands, the gap is increasing between women born abroad and born in the country, while decreasing slightly in others, e.g. ER among men in France and in the Netherlands.

\section{INSERT TABLE 2}

\section{Probit models}

EU-LFS micro-data contains detailed individuals' information on labor market participation for a representative sample of the population on a yearly basis. We rely on the EU-LFS micro-data and econometric tools to identify potential changes in ERs across periods, paying attention to differences 
between the targeted age cohorts (50-54,) 55-59 and 60-64 compared with the benchmark cohort aged 45-49.

We test econometrically to which degree differences in ER levels between cohorts are significant across periods. Considering the group aged 45 to 49 as the counterfactual, we interpret that estimated marginal changes in ER, with respect to the counterfactual as the consequence of reforms undertaken. Equation (1) depicts the general relation we estimate. It assumes that the probability of individual $i$ to be in employment in year $t$ is the expectation of $e m p l_{i t}=1$ conditional on $\Omega_{i t}$, a transformation of a set of explanatory variables. In this case, we use a probit model: the transformation function $\Omega_{i t}$ is assumed to be the cumulative standard normal distribution function $\Phi[$.$] and the explanatory variables individuals' characteristics, age, education, country of birth and$ marital status, represented by dummy variables: ${ }^{10}$

$\operatorname{Pr}\left(\right.$ empl $\left._{i t}=1 \mid \Omega_{i t}\right)=\Phi\left[\alpha+\sum_{j=2}^{4} \beta_{j} \cdot\right.$ age $_{j}+\sum_{k=2}^{3} \gamma_{k} \cdot e d u_{k}+\sum_{l=2}^{2} \delta_{l} \cdot$ birth $_{l}+\sum_{m=2}^{3} \eta_{m}$. stat $\left._{m}\right]$,

where age $_{j}$ indicates the age category, with $j=1,2,3,4$ corresponding to the successive cohorts 45-49, 50-54, 55-59 and 60-64, respectively; $e d u_{k}$ the individual educational attainment dummies, with $k=1,2,3$ corresponding to high (higher than secondary school), medium (secondary school) and low (primary school) levels, respectively; birth the country of birth, with $l=1,2$ indicating if the individual was born in the country she/he currently lives in (Belgium, France, Germany or the Netherlands) or was born abroad, respectively ${ }^{11}$; and stat $_{m}$ the marital status dummies, with $m=1,2,3$ indicating unmarried, married or widowed, respectively. Finally, $\alpha, \beta_{j}, \gamma_{k}, \delta_{l}$ and $\eta_{m}$ are the parameters to be estimated for $j, k, l, m>1$.

Beyond these purely static estimates, our interest is also on how the ER among those 50-54, 55-59, and 60-64 evolved after 2001, compared with changes for the group 45-49, our control group. For this purpose, we estimate for each country, and for female and male separately, a single probit model allowing all the coefficients in equation (1) to vary over the three sub-periods in which we divided the whole period. However, in order to identify the impact of changes from period to period, and for presentation purposes, we proceed in two steps. In a first step, we estimated equation (2) for the period 1997 to 2006 making the distinction between the two sub periods 1997-2001 and 20022006 periods and, in a second step we estimate equation (3) for the period 2002 to 2011 making the distinction between the 2002-2006 and 2007-2011 sub-periods. ${ }^{12}$

In equation (2), per $_{2}=1$ for years 2002-2006, and per $_{2}=0$ for years 1997-2001:

\footnotetext{
${ }^{10}$ Employment is as defined by the derived variable ILOSTAT in the EU-LFS (Eurostat, 2012) - essentially work effort of at least 1 hour during a reference period.

${ }^{11}$ A finer breakdown of the category of people born abroad between those born in EU-15, the rest of the EU and outside of EU would be preferable. However, the relevant indicators cannot be traced harmoniously across time as the EU-LFS data and methodology reflect the change from 15 to 27 members during the period under study, with sample size further limiting such breakdowns into subgroups.

${ }^{12}$ Given the 5-year age brackets in EU-LFS data, our choice of 5-year sub-periods is handy. Proceeding in this way, we obtain a perfect correspondence between sub-periods and 5-year age cohorts, de facto allowing us to trace groups of cohorts across time.
} 


$$
\begin{aligned}
& \operatorname{Pr}\left(\text { empl }_{i t}=1 \mid \Omega_{i t}\right)=\Phi\left[\alpha_{1}+\sum_{j=2}^{4} \beta_{j, 1} \cdot \text { age } e_{j}+\sum_{k=2}^{3} \gamma_{k, l} \cdot \text { edu } u_{k}+\sum_{l=2}^{2} \delta_{l, l} \cdot \text { birth }_{l}+\sum_{m=2}^{3} \eta_{m, l} \cdot \text { stat }_{m}\right. \\
& \left.+\tilde{\alpha}_{2} \cdot \text { per }_{2}+\sum_{j=2}^{4} \tilde{\beta}_{j, 2} \cdot \text { age }_{j, i t} \cdot \text { per }_{2}+\sum_{k=2}^{3} \tilde{\gamma}_{k, 2} \cdot e d u_{k} \cdot \text { per }_{2}+\sum_{l=2}^{2} \tilde{\delta}_{l, 2} \cdot \text { birth }_{l} \cdot \text { per }_{2}+\sum_{m=2}^{3} \tilde{\eta}_{m, 2} . \text { stat }_{m} \cdot \text { per }_{2}\right]
\end{aligned}
$$

where coefficients $\tilde{\alpha}_{2}, \tilde{\beta}_{j, 2}, \tilde{\gamma}_{k, 2}, \tilde{\delta}_{l, 2}$ and $\tilde{\eta}_{m, 2}$ are, by construction, equivalent to differences in variable effects between the second and first sub-period: $\tilde{\alpha}_{2}=\alpha_{2}-\alpha_{1}, \tilde{\beta}_{j, 2}=\beta_{j, 2}-\beta_{j, 1}$, $\tilde{\gamma}_{k, 2}=\gamma_{k, 2}-\gamma_{k, 1}, \tilde{\delta}_{l, 2}=\delta_{l, 2}-\delta_{l, 1}$ and $\tilde{\eta}_{m, 2}=\eta_{m, 2}-\eta_{m, 1}$, respectively.

Our attention focuses on the sign and the statistical significance of coefficients $\tilde{\beta}_{j, 2}$. They allow us to identify changes, from 1997-2001 to 2002-2006, in estimated employment probabilities among older workers, not explained by inter-period general changes, driven mainly by the economic environment and caught by $\tilde{\alpha}_{2}$, nor by changes in employment probabilities explained by education, country of birth and marital status, caught by $\tilde{\gamma}_{k, 2}, \tilde{\delta}_{l, 2}$ and $\tilde{\eta}_{m, 2}$ respectively. We are interested in the sign and the significance of estimated marginal effects on employment probabilities of older age cohorts compared with the 45-49 years old cohort - hinting at any employment effects as a result of the "paradigm" shift in employment policies towards the elderly. Because of the above-mentioned data limitations of the EU-LFS, we only perform this analysis for Belgium, France and the Netherlands.

In a second step, we proceed in the same way for the period 1995 to 2006, making the distinction between the 2002-2006 and 2007-2011 sub-periods. In this case, per $_{3}=1$ for period 2007-2011, and per $_{3}=0$ otherwise:

$$
\begin{aligned}
& \operatorname{Pr}\left(\text { empl }_{i t}=1 \mid \Omega_{i t}\right)=\Phi\left[\alpha_{2}+\sum_{j=2}^{4} \beta_{j, 2} \cdot \text { age } e_{j}+\sum_{k=2}^{3} \gamma_{k, 2} \cdot \text { edu } u_{k}+\sum_{l=2}^{2} \delta_{l, 2} \cdot \text { birth }_{l}+\sum_{m=2}^{3} \eta_{m, 2} \cdot \text { stat }_{m}\right. \\
& \left.+\tilde{\alpha}_{3} \cdot \text { per }_{3}+\sum_{j=2}^{4} \tilde{\beta}_{j, 3} \cdot \text { age }_{j} \cdot \text { per }_{3}+\sum_{k=2}^{3} \tilde{\gamma}_{k, 3} \cdot \text { edu } u_{k} \cdot \text { per }_{3}+\sum_{l=2}^{2} \tilde{\delta}_{l, 3} \cdot \text { birth }_{l} \cdot \text { per }_{3}+\sum_{m=2}^{3} \tilde{\eta}_{m, 3} \cdot \text { stat }_{m} \cdot \text { per }_{3}\right]
\end{aligned}
$$

where $\tilde{\alpha}_{3}=\alpha_{3}-\alpha_{2}, \tilde{\beta}_{j, 3}=\beta_{j, 3}-\beta_{j, 2}, \tilde{\gamma}_{k, 3}=\gamma_{k, 3}-\gamma_{k, 2}, \tilde{\delta}_{l, 3}=\delta_{l, 3}-\delta_{l, 2}$ and $\tilde{\eta}_{m, 3}=\eta_{m, 3}-\eta_{m, 2}$.

We make the assumption that these parameters, in particular the period-specific age parameters $\tilde{\beta}_{j, 3}$ and their corresponding estimated marginal effects on employment probabilities capture the period specific dynamics resulting from either ongoing implementation of reformed labor market policies/regulations and/or the financial crisis.

Tables 3 and 4 report the marginal effects corresponding to probit models (2) and (3) respectively. In both tables, we make the distinction between the reference period, at the top of the table, and the second period, at the bottom. It is important to note that for the reference period the marginal effects correspond to cross-section variations with respect to the reference group (45-49 years old, 
high education, living in the country of birth and unmarried), while for the second period, the marginal effects correspond to variations in these cross-sectional effects across periods.

\section{INSERT TABLE 3}

From the top of Table 3, we observe that the results for the period 1997-2001 confirm the sharp drop in ER among the 55 to 59 and 60 to 64 years old cohorts and in all cases higher slowdown for men than for women. As expected, education and country of birth matters too; in all cases the sign of coefficients are statistically significant. For women and men these effects are rather similar, with the exception of the Netherlands, where the drop in ER is sharper among women with low education ($27.5 \%$ points) and for men born abroad (-16.5\% points), and in France, where to the contrary, the drop is larger among women born abroad (-8.0\% points).

The results at the bottom of Table 3 present the extra effect of period 2002-2006 for the different variables listed - which we refer to as the "crossed" effect (an underlying variable crossed with the second sub-period 2002-2006). When looking at the crossed effect linked to age, we see that the marginal effect of the male cohorts aged 55-59 and 60-64 was positive and significant in all three countries - pointing at a catching-up phenomenon with respect to the baseline group aged 45-49. For women, we observe either no significant gap with respect to the reference cohort (like in Belgium) or a smaller effect than among men ( $+2.3 \%$ points among the 55 to 59 years old in France and near $2 \%$ points in the Netherlands among the 50-54 and 55-59 years old). Remember that our findings are purely descriptive in this sense neither the proof nor the invalidation of any specific policy measure. They rather document that in the aftermath of the Lisbon summit, there has been an increase in employment and some degree of catching up - whether caused by policy change or not.

From the results of Table 3, it is further noticeable that in most cases ER grew faster for low and medium educated workers than for highly educated - all other things being equal. The only exceptions to this pattern are men with medium education in Belgium and men with low and medium education in France.

Table 4 reports similar results for the second period of analysis 2002-2011. Results of the top panel of Table 4 are broadly comparable with those of Table 3. For Germany, which was not present in Table 3, the marginal effects of education and country of birth are all comparable to those observed for the other countries and statistically significant. More remarkable in the case of Germany, is that no major differences appear between the marginal effects across women and men, and that age effects are less dramatic, particularly for the 55 to 59 years old cohort, $-16.5 \%$ and $-18.3 \%$ points compared to drops in ER rates going from $-20 \%$ to near $-35 \%$ points in the neighboring countries. The effect of marital status is rather heterogeneous across periods and countries. ${ }^{13}$

The second part of Table 4 reveals some surprising results. First, our estimates indicate that contrary to expectations, the ER improved from 2007 to 2011 for the population as witnessed by the positive marginal effect of this second sub-period. This is particularly true in Germany ( $\tilde{\alpha}_{3}=+2.3 \%$ and $\tilde{\alpha}_{3}=$ $+4.0 \%$ points, respectively for women and men) and among women in Belgium ( $+2.3 \%$ points) and the Netherlands ( $+2.9 \%$ points) - showing that the aftermath of the financial crisis has not

\footnotetext{
${ }^{13}$ For Germany, we performed sensitivity analysis by restricting the sample to Western Germany - with substantially unchanged results.
} 
everywhere been a period of low and decreasing employment. Quite to the contrary, some countries seem to have made important advances in the post-crisis world - be they the result of explicit policy measures (such as continued implementation of employment strategies) or not.

Second, we observe a positive and significant additional effect among the aged cohorts. Among the 55 to 59 years old the marginal effect, corresponding to the $\widetilde{\beta}_{3,3}$ coefficient, are in several cases higher than $5 \%$ points (the only exceptions are men in Germany and women in France), while for the 60 to 64 years old (coefficient $\tilde{\beta}_{4,3}$ ) the marginal rates are between $5 \%$ to $10 \%$ points for Germany and the Netherlands, and between $1 \%$ and $4 \%$ points for Belgium and France.

Looking at groups of individuals that are often associated with increased vulnerabilities - namely the less skilled and those born abroad - they seem to have fared less favorably in the aftermath of the financial crisis - ceteris paribus. The coefficients $\tilde{\gamma}_{3,3}$ and $\tilde{\delta}_{2,3}$ are in both cases negative or statistically non-significant. It is interesting to notice that this is exactly the reverse of what we observed in Table 3 for the $\tilde{\gamma}_{3,2}$ and $\tilde{\delta}_{2,2}$ coefficients, that were in nearly all cases positive for the 2002-2006 periodindicating a catch-up of those groups in the run-up to the financial crisis.

\section{INSERT TABLE 4}

The appendix provides some alternative estimation using a difference in difference approach (DID) broadly confirming the above results. More specifically, one possible weakness of the present analysis could be that it takes different cohorts at different time-periods as independent. Expressed differently, the results reported were estimated as if the 5-year age cohorts were composed of different people each year over the whole period. Conceptually, however, this is somewhat incorrect as the same birth cohort observed age 55 in 2002, e.g., will again be present in 2007 aged 60.

As the EU-LFS micro-data can be weighted to be representative of the population at large, in the Appendix we build a pseudo-panel to identify variations in ER for successive cohorts as they age. Using this information, we test the potential changes in ER, but this time using a difference in difference (DID) approach which allow controlling for cohorts' specificity or, in other words, cohorts heterogeneity. This gain however comes at the cost of having to rely on a pseudo-panel assumption and less readability of results.

\section{Hours of work analysis}

The present section proposes a complementary analysis of hours of work. The starting point is that merely looking at ERs for measuring labor utilization gives a very partial picture of reality - be it for the population at large or those aged $50+$. There is ample potential for a general link between employment and hours of work. For the $50+$ population more specifically, our working hypothesis is that substitution behavior is most certainly an unneglectable issue.

The current policy debate seems to confirm our working hypothesis: reduced pre-retirement work schedules, part-time retirement, etc. are all reminders of the conceptual relevance of taking hours of work into account when evaluating government policies. For example, if increased employment comes at the cost of lower hours of work, the expected/projected effect on individuals, the 
government budget, economic growth, etc. could be very different (less favorable) when taking both factors into account than when merely looking at the ER as the sole indicator.

We thus investigate two specific questions: (1) Did the increase in ER (as observed in the previous section) come at the "cost" of reduced work hours for those working? (2) How did total hours of work evolve?

\section{Individual work hours}

We use information on usual hours of work reported in EU-LFS micro-data and estimate a Heckman (1979) selection model with usual hours of work as the dependent variable. To take into account a potential selection bias, due to the observability of data (hours at work) exclusively for individuals in employment, the model includes among explanatory variables the inverse Mills ratio derived from the estimation of ER probabilities under the probit model presented in Section 3. For estimation purposes, we rely on the full maximum likelihood Heckman procedure available in STATA.

As for the study of ER in Section 3, we proceed in two steps. In the first step, we estimate a model for the first two sub-periods, 2002-2006 vs. 1997-2001, and in a second step, 2007-2011 vs. 2002-2006. Equation 4 and 5 present the parametric linear relation we choose to model hours of work for periods 1997-2006 and 2001-2011, respectively: ${ }^{14}$

$$
\begin{aligned}
& \text { hour }_{i t}=\alpha_{1}+\sum_{j=2}^{4} \beta_{j, 1} . \text { age }_{j, i t}+\sum_{k=2}^{3} \gamma_{k, 1} . e d u_{k, i t}+\sum_{l=2}^{2} \delta_{l, 1} . \text { birth }_{l, i t}+\tau_{1} . \text { senior }_{i t}+ \\
& \tilde{\alpha}_{2} \cdot \text { per }_{2}+\sum_{j=2}^{4} \tilde{\beta}_{j, 2} \cdot \text { age }_{j, i t} \cdot \text { per }_{2}+\sum_{k=2}^{3} \tilde{\gamma}_{k, 2} \cdot \text { edu } u_{k, i t} \cdot \text { per }_{2}+\sum_{l=2}^{2} \tilde{\delta}_{l, 2} \cdot \text { birth }_{2, i t} \cdot \text { per }_{2}+\tilde{\tau}_{2} \cdot \text { senior }_{i t} \cdot \text { per }_{2}, \\
& \text { hour }_{i t}=\alpha_{2}+\sum_{j=2}^{4} \beta_{j, 2} . \text { age }_{j, i t}+\sum_{k=2}^{3} \gamma_{k, 2} . e d u_{k, i t}+\sum_{l=2}^{2} \delta_{l, 2} . \text { birth }_{l, i t}+\tau_{2} . \text { senior }_{i t}+ \\
& \tilde{\alpha}_{3} \cdot \text { per }_{3}+\sum_{j=2}^{4} \tilde{\beta}_{j, 3} \cdot \text { age }_{j, i t} \cdot \text { per }_{3}+\sum_{k=2}^{3} \tilde{\gamma}_{k, 3} \cdot \text { edu } u_{k, i t} \cdot \text { per }_{3}+\sum_{l=2}^{2} \tilde{\delta}_{l, 3} \cdot \text { birth } h_{3, i t} \cdot \text { per }_{3}+\tilde{\tau}_{3} \cdot \text { senior }_{i t} \cdot \text { per }_{3} \text {, }
\end{aligned}
$$

where hour $_{i t}$ corresponds to the number of hours per week usually at work, senior $r_{i t}$ to seniority in the current employment in years, and the other variables are as defined before. To allow model identification, we assume that marital status, an explanatory variable in the ER model, is not relevant to explain hours of work. We are aware that this is a strong assumption, but we did not identify any other variable in the EU-LFS better suited for identification purposes. ${ }^{15}$

In Tables 5 and 6 we report the estimated coefficients for sub-periods 1997-2006 and 2002-2011, respectively. In all cases the Mills ratio appears to be positive and statistically significant indicating that the results would be biased upward without taking into account a potential selection bias. Also,

\footnotetext{
${ }^{14}$ Note that we use the same parameter notation for probit models (equations 1 and 2) and for OLS models (equations 4 and 5) for simplification purposes.

${ }^{15}$ We also estimated the same Heckman selection models including the marital status dummy variables. Results were in most cases very close to those presented here.
} 
for the period 2002-2006 the direct effects $\tilde{\alpha}_{2}$ indicate in all cases an increasing, and in some cases statistically significant path in the hours at work. This is the case of women in Belgium and France, +1.88 hours and +2.07 respectively, and of men in France and in the Netherlands, +2.54 hours and +0.44 respectively. A similar increasing path is observed for 2007-2011 for women and men in Belgium and for men in France. By construction, these effects are associated with the reference group in the analysis, in this case the 45 to 49 years old. For the other time-independent explanatory variables, such as age, it is difficult to identify a general pattern of direct effects: women in France and men in Germany and the Netherlands appear to work fewer hours when ageing. Also, less educated workers work in general fewer hours than high qualified workers, as expected. Finally, seniority appears in general associated with more hours at work.

\section{INSERT TABLE 5 AND 6}

Looking at crossed effects, we can identify period-specific effects of changes in these independent variables - either from 1997-2001 to 2002-2006 (Table 5) or from 2002-2006 to 2007-2011 (Table 6). As in the previous Sections, we are interested in the sign and the significance of estimated marginal effects on hours of work, particularly crossed effects between age and periods. For example, we observe that for the case of Belgium nearly all groups show a decline in hours compared to the reference group. This effect nearly represents 1 hour each period for the 55-59 years old, with an even stronger effect for the age group 60-64 where $\tilde{\beta}_{4,2}=-2.74$ hours for men in 2002-2006. For France and the Netherlands the results are contrasted, positive and statistically significant for women and men during 2002-2006, and negative for 2007-2011. Also for Germany, where the results are only available for 2007-2011, there is a downward trend, that is however only statistically significant for men. ${ }^{16}$

Finally, crossed effects between period and education indicate a significant decrease in hours worked per week among less skilled workers in both periods. The only exception is women with low education in the Netherlands during 2002-2006 where the corresponding value is $\tilde{\lambda}_{3,2}=+0.66$. To be born abroad has no clear universal pattern of effects. Broadly speaking, these latter results indicate that the lower educated have overall seen rather pronounced declines in their working hours, and this across all countries studied. Being born abroad on the other hand has no clear effect on hours of work, which contrasts with the results in terms of ERs where both vulnerable groups were more heavily affected after the onset of the financial crisis.

These latter findings have immediate policy relevance. They confirm our working hypothesis that the reliance on a single indicator such as ER for evaluating employment performance might lead to inadequate conclusions and thus inappropriate policies - as leaving aside work intensity.

\section{Total hours of work}

Now that we have established that hours of work do change, the second question remains unanswered: what is the combined effect of both the ER and hours change in terms of total hours of work? We propose a decomposition analysis that separates out the effect of three factors:

\footnotetext{
${ }^{16}$ For Germany, we again performed sensitivity analysis by restricting the sample to Western Germany - with substantially unchanged results.
} 
demographic trends, employment rate and hours of work. As before, for reasons of clarity and comparability, we limit our attention to the population $55-64$. We proceed by micro-simulation analysis to evaluate the change in total hours of work.

More specifically, we proceed in three steps. In the first step, we compute the change from subperiod to sub-period in the total number of hours of work for a particular age-gender group assuming that ER and hours of work are kept constant for a given set of individuals attributes (education, country of birth, marital status and seniority). This gives us an estimation of the change in total hours of work that is merely due to what we refer to as the demographic change, effectively changes in cohort size and the composition of the cohort according to the above attributes. ${ }^{17}$

In a second step, we estimate the variation in total hours of work resulting from changes in ERs between sub-periods, expressed differently along the extensive margin. For this purpose we use the coefficients of probit equations 2 and 3 to predict changes in employment rates for each sub-period (1997-2001 and 2002-2006 for equation 2 and 2002-2006 and 2007-2011 for equation 3) - keeping both the demographic composition and the hours of work constant. The difference between these two values gives an estimation of the extensive change in employment.

The third step consists in the estimation of changes in total hours of work due to changes in individual hours of work, or expressed differently the intensive margin. As in the previous step we proceed by micro-simulation using the same counterfactual. To be more precise, we use the coefficients of equations 4 and 5 to predict changes in total hours of work for each sub-period keeping both the demographic composition and the employment constant. The difference between these estimations corresponds to the intensive change.

In Table 7 we report the results obtained for the 55-59 and 60-64 age cohorts (by sex) for the four countries - and this for both periods of study 1997-2006 and 2002-2011. A reported value of 1.10 represents a $10 \%$ increase from one sub-period to the next, a value of 0.95 a $5 \%$ decrease. By construction, the total rate of change corresponds in each case to the product of the demographic, intensive and extensive changes. We are particularly interested on the net result of extensive and intensive changes, reported in the last columns of Table 7 as behavioral change - as they are the only endogenous parameters - hence of particular policy relevance.

\section{INSERT TABLE 7}

We observe that total hours of work among the cohorts was driven mainly by demographic change, baby-boomers arriving first, in 2001-2006, to the 55-59 age cohort and later, in 2007-2011, to the 6064 cohort, with the only exception of Germany where - due to its earlier demographic cycle - the baby boom generation no longer appears as such in the data. Behavioral change is always positively signed and is generally larger for women than for men. France provides the noticeable deviation to this pattern with substantially stronger employment effects for men ultimately leading to a larger behavioral effect for men than for women.

Table 7 also illustrates that positive changes at the extensive margin (in ERs) have over the period of study largely compensated for any observed negative changes at the intensive margin (hours of

\footnotetext{
${ }^{17}$ Technically, we simulate the change in a given variable $X$ while keeping variables $Y$ and $Z$ at their starting and/or finishing levels, and then take a geometric average.
} 
work). This result indicates that overall, the older cohorts are contributing to a larger degree to the economic activity of the countries, and hence also to the financing of its public and social sectors. However, the results also indicate substantial offsetting behavior. This is particularly true in Belgium, where for all age groups and all periods the change at the intensive margin has been negative, reaching $8 \%$ for women aged $55-59$ in the first period.

\section{Conclusions}

European welfare states are under stress: demographic and social changes are leading to increasing demands in terms of expenditures at a time when the population in working age is shrinking. In the face of this observation, academic economists have been promoting the idea of increasing the employment rate of the elderly as one key policy area. With the arrival of the Open Method of Coordination and the Lisbon criteria in 2001, this policy objective has also been put on the agenda of policy makers - either explicitly or implicitly.

The present paper provides a fresh look at the question using European Union Labour Force Survey micro-data. It innovates with respect to the literature in two areas. First, it takes a comparative approach between Belgium and its neighbors France, Germany and the Netherlands. Second, it extends the usual benchmarking based on employment rates alone to also include hours of work data.

Our results are twofold. First, we construct probit models of employment and show that older workers aged 50+ have by and large a significantly larger increase in employment than the one observed for the general population over the time period 1997-2011. Our findings indicate some "catching-up" phenomenon with older cohorts looking increasingly like prime-age ones. We find substantial differences between men and women, pointing to the need to take the gender dimension into account when considering labor market policies. We further find that vulnerable groups, such as less educated and first-generation immigrants, fared less well relative to the reference groups.

Second, we complement the employment rate analysis by an hours-of-work analysis. More specifically, we investigate to which degree - if any - there has been substitution between employment and hours of work for the individuals under study. For this purpose, we estimate a Heckman selection model and evaluate the changes in hours of work. The results show that for some groups in the 55-64 age bracket, reductions in observed average hours of work can be as important as $8 \%$ for the case of Belgium.

To evaluate the relative importance of the above factors, we complete the analysis by a microsimulation approach that decomposes the change in total hours of work for the various age-sex groups into a demographic, extensive (employment) and intensive (hours) margin. Our results indicate that in the period of observation, changes in employment rates have been sufficiently strong to offset any negative hours of work tendencies.

Our results should be seen as warrant for caution. They mean that a given observed increase in employment rates might hide very different realities (different work intensities). As a result, a policy merely focused on employment rates might be heavily misguided. 
Blundell R. and T. MaCurdy (1999), "Labor Supply: A Review of Alternative Approaches", in Ashenfelter O.C. and D. Card, ed., Handbook of Labor Economics, Volume 3A, Chapter 27, 1559-1695.

Bonsang, E., Perelman, S. and S. Adam (2012), “Does retirement affect cognitive functioning?", Journal of Health Economics, 31, 3, 490-501.

European Commission (1999), "Towards a Europe for all ages. Promoting Prosperity and Intergenerational Solidarity", Brussels 21.05.1999 COM(1999) 221, final, http://ec.europa.eu/employment social/social situation/docs/com221 en.pdf

European Council (2000), "Lisbon European Council, Presidency Conclusions, 23 and 24 March 2000", http://www.consilium.europa.eu/uedocs/cms data/docs/pressdata/en/ec/00100-r1.en0.htm

European Council (2001), "European Council Meeting in Laeken, Presidency Conclusions, 14 and 15 December 2001",

http://www.consilium.europa.eu/uedocs/cms data/docs/pressdata/en/ec/68827.pdf

Gruber, J. and D. Wise (eds.) (2004), "Social Security Programs and Retirement around the World. Micro-estimation", NBER and University of Chicago Press.

Gruber, J. and D. Wise (eds.) (2010), "Social Security Programs and Retirement around the World. The Relationship to Youth Employment", NBER and University of Chicago Press.

European Commission (2012), "European Year for Active Ageing and Solidarity between Generations 2012", http://europa.eu/ey2012.

Eurostat (2012), "EU Labour Force Survey database User guide".

Heckman, J. (1979), "Sample selection bias as a specification error", Econometrica 47, 1, 153-161.

Lefebvre, M. (2013), "Social Security and Retirement: the Relationship between Workers, Firms and Government", Annals of Public and Cooperative Economics, 84(1), 43-61.

Steiner, V. (2015), "Recent labour market developments, pension reforms, and early retirement in Germany", paper presented at IAB Workshop "Retirement policy reform and the labour market for older workers in a comparative perspective", February 19-20, 2015.

WHO (2002), "Active Ageing: A Policy Framework, A contribution of the World Health Organization to the Second United Nations World Assembly on Ageing", Madrid, Spain.

Wise, D. (editor) (2016), "Social Security Programs and Retirement around the World. Disability Insurance Programs and Retirement", NBER and University of Chicago Press. 
For this analysis we use all the individuals information available annually in the EU-LFS. Given the restrictions on personal information, individuals are identified as members of 5-year cohorts and not by the exact year of birth. As a consequence, people born the same year (a one-year cohort) belongs to the same 5-years age group over 5 years, e.g. the population born in 1950 are included in the 50 to 54 years old group from 2000 to 2004 .

DID equation 1.a is estimated using OLS, separately for women and men for Belgium, France and, on a shorter period, for the Netherlands. ${ }^{18}$ In order to perform DID, we compute for every year $t$ and for each 5-year age-cohort $j$ ER variations from 5-years before, that is when they belonged to the younger age category. To be able to compare the ER decline with age for the period before 2001, we computed ER change using available information from the period 1992-1996 for Belgium, and for the period 1993-1996 for France. For the Netherlands data is only available from 1997, as indicated before.

Equation 1.a presents the general form of the DID estimation:

$$
\Delta E R_{s t}=\alpha_{1}+\sum_{p=2}^{3} \tilde{\alpha}_{p} \cdot \text { per }_{p}+\sum_{j=2}^{4} \beta_{j, 1} . a g e_{j}+\sum_{p=2}^{3} \sum_{j=2}^{4} \tilde{\beta}_{j, p} \cdot \text { per }_{p} \cdot a g e_{j}+\varepsilon_{s t},
$$

where $\Delta E R_{s, t}$ indicates the observed change in the rate of employment over the previous 5 years, from year $t-5$ to $t$, corresponding to a category $s$ in the population identified by its age (45-49, 50-54, 55-59 or 60-64 years old), its level of education (low, medium or high), the place of birth (same country or abroad) and marital status (unmarried, married or widowed). That is, 72 observations by year and by gender for each country computed from EU-LFS micro-data. $\triangle E R$ for the 45 to 49 years old is computed making the difference with ER observed for the same cohort 5 years before, when aged 40 to 44 years old.

In equation 1.a, periods and age categories are represented by dummy variables: per $_{p}$ corresponds to the 5-year periods [ $p=1$ (1997-2001), 2 (2002-2006) or 3 (2007-2011)] and $a g e_{j}$ to age categories [j=1 (45-49), j=2 (50-54), 3 (55-59) or 4 (60-64)]. Finally, $\alpha_{1}, \tilde{\alpha}_{p}, \beta_{j, l}$ and $\tilde{\beta}_{j, p}$ are the parameters to be estimated by OLS, and $\varepsilon_{s t}$ the random error term assumed to be normally distributed $\left[N\left(0, \sigma^{2}\right)\right]$. We are particularly interested on the sign and statistical significance of parameters $\tilde{\beta}_{j, p}$. By construction, they allow identifying differences in ER changes when aging, and across periods, for successive cohorts in the 50 to 64 years old age categories. Note that the difference and difference analysis is estimated in one step for the three periods, therefore coefficients

\footnotetext{
${ }^{18}$ For Belgium and France, we rely on data available from 1992 and 1993, respectively. For the Netherlands the first year available is 1997. Data for Germany is only available from 2002 on, which does not allow us to run DID, even for the last 5-year period.
} 
$\tilde{\alpha}_{2}\left[=\alpha_{2}-\alpha_{1}\right], \tilde{\alpha}_{3}\left[=\alpha_{3}-\alpha_{1}\right], \tilde{\beta}_{j, 2}\left[=\beta_{j, 2}-\beta_{j, 1}\right]$ and $\tilde{\beta}_{j, 3}\left[=\beta_{j, 3}-\beta_{j, 1}\right]$ are computed keeping 1997-2001 as the reference period, for Belgium and France.

The estimates are reported in Table A.1. First, the top panel reveals that the ER improved significantly for women in France in 2002-2006 ( $\alpha_{2}=+2.4 \%$ points) and 2007-2011 ( $\alpha_{3}=2.8 \%$ points). On the contrary, it decreased significantly for women in the Netherlands in 2007-2011 ( $\alpha_{3}=-2.9 \%$ points). ${ }^{19}$ We further observe a negative and statistically significant effect of aging, particularly after 55 years, but not as strong as the instantaneous (cross-section) age effects reported in Tables 3 and 4. However, like in the probit models, there are large differences between men and women in Belgium and France. E.g., in Belgium $\beta_{3}=-24.7$ and $-10.8 \%$ points for men and women respectively the 55-59 age group.

Second, turning to the crossed effect coefficients $\tilde{\beta}_{j, m}$ for the period 2002-2006 we identify negative effects for women and positive effect for men, both in Belgium and France, with only the coefficients for France displaying statistical significance. For the period 2007-2011, the results are also contrasted for women and men in Belgium and France. E.g., for women aged 60 to 64 years old, the effects are in both countries negative and significant with $\tilde{\beta}_{4,3}=-4.3 \%$ and $-6.2 \%$ points, respectively. ${ }^{20}$ For men, the overall picture is similar to that of table 4 , namely positive and significant effects for men aged 50-59 in Belgium and aged 55-64 in France. Finally, for the Netherlands, the parameters are positive and statistically significant both for women and men aged $55-59, \tilde{\beta}_{3,3}=+3.7 \%$ and $+3.4 \%$ points, respectively, as well as for men aged $60-64$ years old, $\tilde{\beta}_{4,3}=+3.4 \%$ points, and for women aged 50 54 years old, $\tilde{\beta}_{2,3}=+2.5 \%$ points. These results thus confirm, with a few exceptions, the results presented in Section 3.

INSERT TABLE A.1

\footnotetext{
${ }^{19}$ For the Netherlands, $\tilde{\alpha}_{3}\left[=\alpha_{3}-\alpha_{2}\right]$, and $\tilde{\beta}_{j, 3}\left[=\beta_{j, 3}-\beta_{j, 2}\right]$ given the that the reference period for the latter country is 2002-2006.

${ }^{20}$ The only exception correspond to the $55-59$ years old women in France, where $\tilde{\beta}_{4,3}=+2.1 \%$ points.
} 
Figure 1. Employment rate
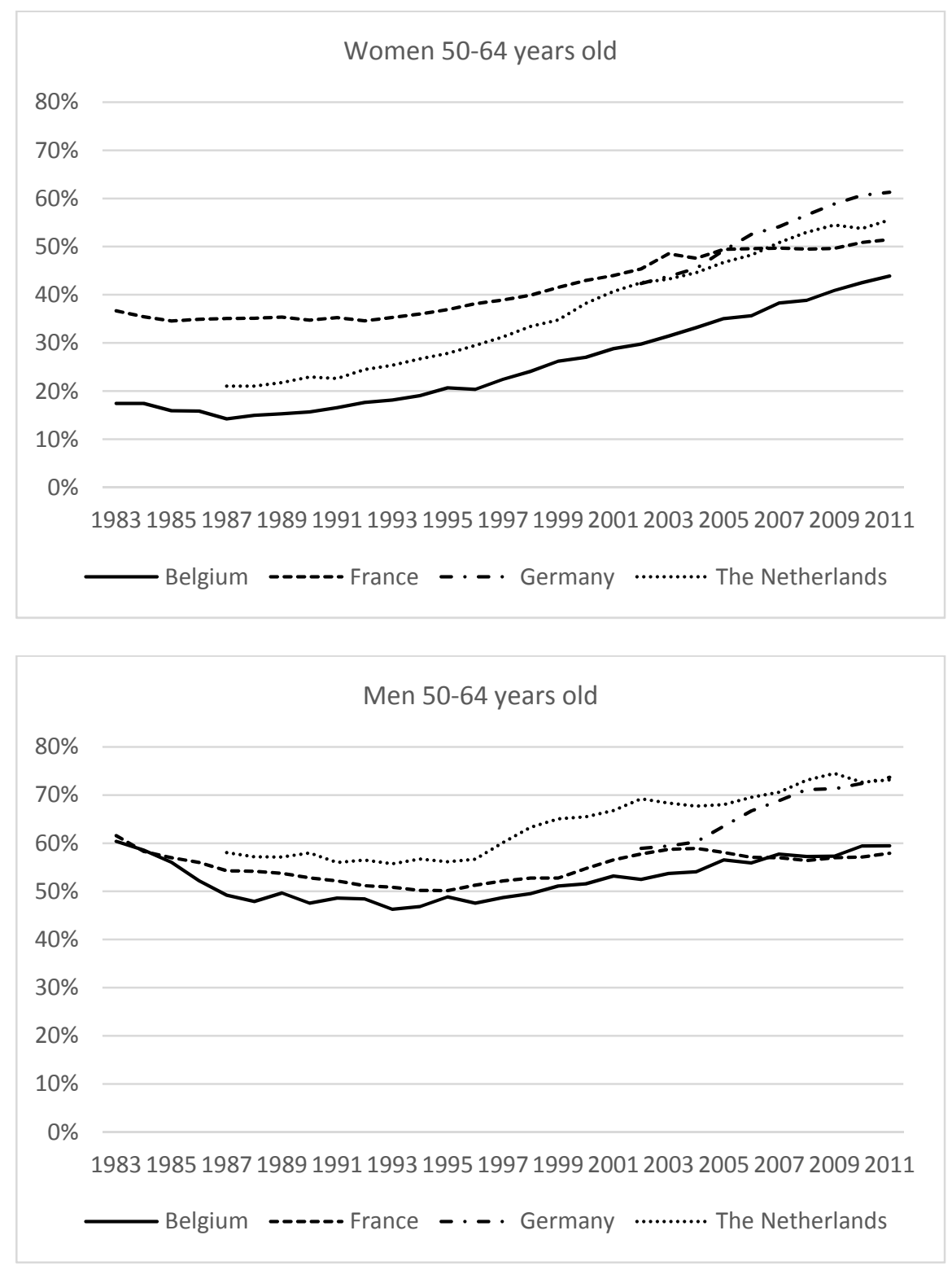

Source: Author's calculations based on EU-LFS micro-data. 
Figure 2. Average usual working hours

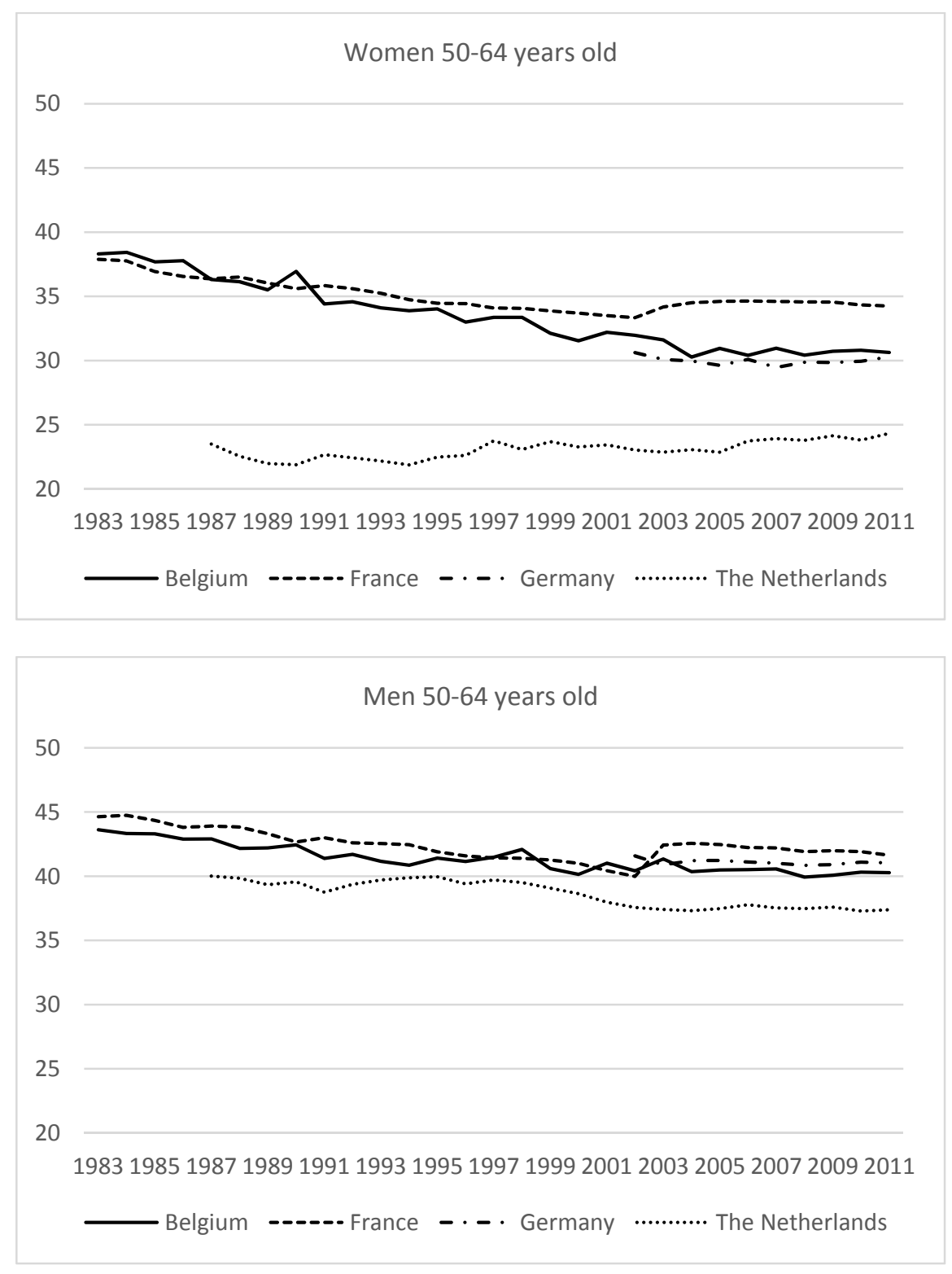

Source: Authors' calculations based on EU-LFS micro-data. 
Figure 3. Employment rate by age-group

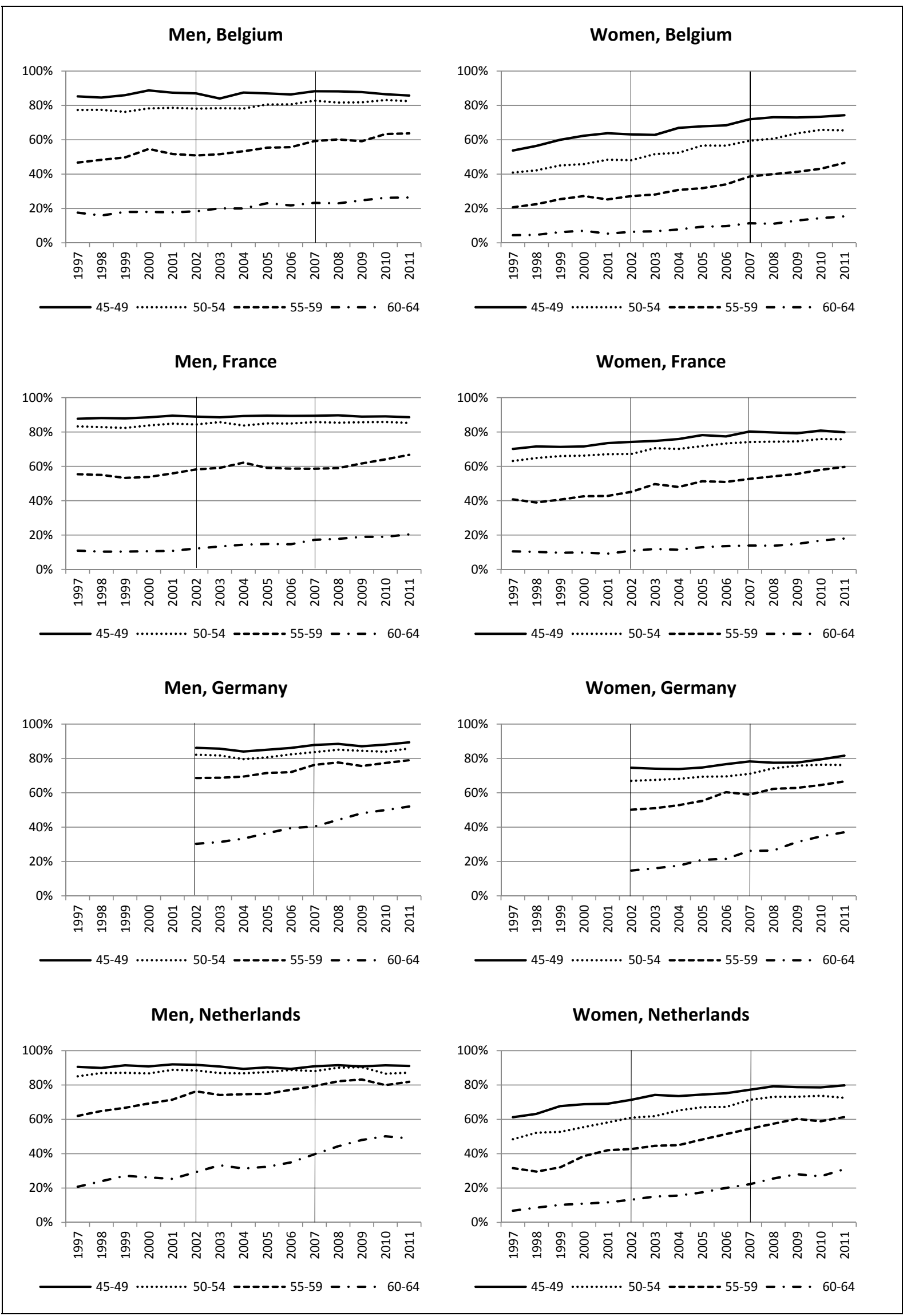

Source: Authors' calculations based on EU-LFS micro-data 
Table 1. Employment rate by education, 45-64 years old

\begin{tabular}{|l|ccc|ccc|}
\hline \multirow{2}{*}{ Education } & \multicolumn{7}{c|}{ Men } & \multicolumn{3}{c|}{ Women } \\
\cline { 2 - 7 } & $1997-2001$ & $2002-2006$ & $2007-2011$ & $1997-2001$ & $2002-2006$ & $2007-2011$ \\
\hline Low & $48.9 \%$ & $51.5 \%$ & $52.7 \%$ & $23.7 \%$ & $28.7 \%$ & $32.7 \%$ \\
Medium & $70.7 \%$ & $71.2 \%$ & $71.0 \%$ & $44.0 \%$ & $50.9 \%$ & $56.3 \%$ \\
High & $80.7 \%$ & $78.5 \%$ & $80.6 \%$ & $62.1 \%$ & $64.1 \%$ & $69.2 \%$ \\
\hline \multicolumn{7}{|c|}{ Brance } \\
\hline Low & $54.6 \%$ & $57.9 \%$ & $55.7 \%$ & $41.7 \%$ & $46.9 \%$ & $47.0 \%$ \\
Medium & $69.7 \%$ & $70.1 \%$ & $68.2 \%$ & $58.1 \%$ & $61.8 \%$ & $63.7 \%$ \\
\hline High & $81.2 \%$ & $80.1 \%$ & $78.6 \%$ & $71.3 \%$ & $71.3 \%$ & $71.3 \%$ \\
\hline Low & - & $53.0 \%$ & $59.0 \%$ & - & $39.2 \%$ & $47.1 \%$ \\
Medium & - & $66.4 \%$ & $75.0 \%$ & - & $56.1 \%$ & $64.9 \%$ \\
High & - & $79.8 \%$ & $85.8 \%$ & - & $72.5 \%$ & $78.9 \%$ \\
\hline \multicolumn{7}{|c|}{ Germany } \\
\hline Low & $63.0 \%$ & $67.3 \%$ & $70.1 \%$ & $32.9 \%$ & $39.2 \%$ & $44.5 \%$ \\
Medium & $74.1 \%$ & $75.1 \%$ & $78.4 \%$ & $52.8 \%$ & $60.0 \%$ & $66.7 \%$ \\
High & $82.3 \%$ & $81.6 \%$ & $84.2 \%$ & $68.5 \%$ & $72.5 \%$ & $77.1 \%$ \\
\hline
\end{tabular}

Source: Authors' calculations based on EU-LFS micro-data

Table 2. Employment rate by country of birth, $45-64$ years old

\begin{tabular}{|l|ccc|ccc|}
\hline \multirow{2}{*}{$\begin{array}{l}\text { Country of } \\
\text { birth }\end{array}$} & \multicolumn{7}{c|}{ Men } & \multicolumn{3}{c|}{ Women } \\
\cline { 2 - 7 } & $1997-2001$ & $2002-2006$ & $2007-2011$ & $1997-2001$ & $2002-2006$ & $2007-2011$ \\
\hline Belgium & $62.6 \%$ & $65.4 \%$ & $67.8 \%$ & $36.4 \%$ & $43.9 \%$ & $51.6 \%$ \\
Abroad & $53.5 \%$ & $54.8 \%$ & $58.5 \%$ & $28.3 \%$ & $34.3 \%$ & $39.7 \%$ \\
\hline \multicolumn{7}{|c|}{ France } \\
\hline France & $65.4 \%$ & $67.5 \%$ & $66.0 \%$ & $52.2 \%$ & $57.2 \%$ & $59.1 \%$ \\
Abroad & $61.7 \%$ & $63.6 \%$ & $63.8 \%$ & $43.3 \%$ & $49.7 \%$ & $52.5 \%$ \\
\hline \multicolumn{7}{|c|}{ Germany } \\
\hline Germany & - & $70.2 \%$ & $77.9 \%$ & - & $66.1 \%$ \\
Abroad & - & $62.1 \%$ & $69.5 \%$ & - & $55.1 \%$ \\
\hline \multicolumn{7}{|c|}{ Netherlands } \\
\hline Netherlands & $73.8 \%$ & $76.1 \%$ & $45.1 \%$ & $61.6 \%$ \\
Abroad & $59.5 \%$ & $64.0 \%$ & $68.2 \%$ & $41.3 \%$ & $47.2 \%$ & $53.2 \%$ \\
\hline
\end{tabular}

Source: Authors' calculations based on EU-LFS micro-data 
Table 3. Probit model employment determinants.

Period 1997-2006, by country and sex. Estimated marginal effects in \% points.

\begin{tabular}{|c|c|c|c|c|c|c|}
\hline \multirow{2}{*}{ Variable } & \multicolumn{2}{|c|}{ Belgium } & \multicolumn{2}{|c|}{ France } & \multicolumn{2}{|c|}{ The Netherlands } \\
\hline & Women & Men & Women & Men & Women & Men \\
\hline \multicolumn{7}{|c|}{ Period 1997-2001 } \\
\hline Intercept $\left(\alpha_{1}\right)$ & $86.5^{* * *}$ & $91.8^{* * *}$ & $89.1^{* * *}$ & $91.6^{* * *}$ & $87.7^{* * *}$ & $90.8^{* * *}$ \\
\hline \multicolumn{7}{|c|}{ Age (Ref: 45-49) } \\
\hline $50-54\left(\beta_{2,1}\right)$ & $-8.6^{* * *}$ & $-10.0^{* * *}$ & $-4.0^{* * *}$ & $-6.6^{* * *}$ & $-8.3^{* * *}$ & $-6.9^{* * *}$ \\
\hline $55-59\left(\beta_{3,1}\right)$ & $-28.5^{* * *}$ & $-40.0^{* * *}$ & $-24.8^{* * *}$ & $-39.7^{* * *}$ & $-24.1^{* * *}$ & $-31.7^{* * *}$ \\
\hline $60-64\left(\beta_{4,1}\right)$ & $-60.9^{* * *}$ & $-69.2^{* * *}$ & $-63.7^{* * *}$ & $-78.0^{* * *}$ & $-57.2^{* * *}$ & $-70.5^{* * *}$ \\
\hline \multicolumn{7}{|c|}{ Education (Ref: High) } \\
\hline $\operatorname{Medium}\left(\gamma_{2,1}\right)$ & $-14.0^{* * *}$ & $-12.0^{* * *}$ & $-9.7^{* * *}$ & $-14.2^{* * *}$ & $-11.1^{* * *}$ & $-8.7^{* * *}$ \\
\hline $\operatorname{Low}\left(\gamma_{2,1}\right)$ & $-30.4^{* * *}$ & $-29.1^{* * *}$ & $-18.6^{* * *}$ & $-23.4^{* * *}$ & $-27.5^{* * *}$ & $-18.3^{* * *}$ \\
\hline \multicolumn{7}{|c|}{ Country of birth (Ref: Country) } \\
\hline $\operatorname{Abroad}\left(\delta_{2,1}\right)$ & $-7.3^{* * *}$ & $-11.2^{* * *}$ & $-8.0^{* * *}$ & $-2.9^{* * *}$ & $-7.4^{* * *}$ & $-16.5^{* * *}$ \\
\hline \multicolumn{7}{|c|}{ Marital status (Ref. single) } \\
\hline Married $\left(\eta_{2,1}\right)$ & $-9.6^{* * *}$ & +8.3 & $-6.8^{* * *}$ & $+9.0^{* * *}$ & $-6.3^{* * *}$ & $+9.5^{* * *}$ \\
\hline Widow $\left(\eta_{3,1}\right)$ & $-5.0^{* * *}$ & $+0.8^{* * *}$ & $-1.9^{* * *}$ & $+2.7^{* * *}$ & $-5.1^{* * *}$ & $+2.7^{* * *}$ \\
\hline \multicolumn{7}{|c|}{ Period (Ref: 1997-2001) } \\
\hline $2002-2006\left(\tilde{\alpha}_{2}\right)$ & +0.2 & -0.6 & +0.1 & $+1.2^{*}$ & $+2.0^{* *}$ & $+2.5^{* * *}$ \\
\hline \multicolumn{7}{|c|}{ Crossed effects (2002-2006) } \\
\hline \multicolumn{7}{|c|}{ Age (Ref: 45-49) } \\
\hline $50-54\left(\tilde{\beta}_{2,2}\right)$ & +1.1 & +1.5 & +0.1 & +0.6 & $+2.1^{* * *}$ & $+1.5^{* *}$ \\
\hline $55-59\left(\tilde{\beta}_{3,2}\right)$ & -0.8 & $+4.1^{* * *}$ & $+2.3^{* * *}$ & $+2.8^{* * *}$ & $+1.7^{* *}$ & $+7.4^{* * *}$ \\
\hline $60-64\left(\tilde{\beta}_{4,2}\right)$ & +0.5 & $+1.7^{* *}$ & -0.5 & $+2.1^{* * *}$ & +1.5 & $+3.4^{* * *}$ \\
\hline \multicolumn{7}{|c|}{ Education (Ref: High) } \\
\hline $\operatorname{Medium}\left(\tilde{\gamma}_{2,2}\right)$ & $+2.9^{* * *}$ & +1.0 & $+2.4^{* * *}$ & +0.6 & $+1.3^{*}$ & $+1.5^{* *}$ \\
\hline $\operatorname{Low}\left(\tilde{\gamma}_{3,2}\right)$ & $+2.3^{* *}$ & $+2.6^{* *}$ & $+1.3^{* *}$ & +1.0 & $+2.3^{* * *}$ & $+4.8^{* * *}$ \\
\hline \multicolumn{7}{|c|}{ Country of birth (Ref: Country) } \\
\hline $\operatorname{Abroad}\left(\tilde{\delta}_{2,2}\right)$ & -0.8 & +0.8 & $+1.2^{* *}$ & $+1.2^{* *}$ & -0.1 & $+4.3^{* * *}$ \\
\hline \multicolumn{7}{|c|}{ Marital status (Ref. single) } \\
\hline $\operatorname{Married}\left(\tilde{\eta}_{2,2}\right)$ & $+5.2^{* * *}$ & -0.1 & $+2.3^{* * *}$ & $-1.1^{* * *}$ & $+3.4^{* * *}$ & $-1.1^{* * *}$ \\
\hline $\operatorname{Widow}\left(\tilde{\eta}_{3,2}\right)$ & $+3.1^{* *}$ & $+2.5^{* *}$ & +0.5 & +0.1 & $+4.1^{* * *}$ & -1.1 \\
\hline \multicolumn{7}{|c|}{ Sample size } \\
\hline \# obs. (x 1000) & 72.9 & 69.2 & 240.7 & 225.8 & 171.2 & 172.1 \\
\hline
\end{tabular}

Notes: In italic, estimated employment probability in \% points for the reference category.

${ }_{* * *, * *, *}$ Statistically significant coefficients at $1 \%, 5 \%$ and $10 \%$ thresholds $\left(\chi^{2}\right.$ test) respectively (robust estimation). 
Table 4. Probit model employment determinants.

Period 2002-2011, by country and sex. Estimated marginal effects in \% points.

\begin{tabular}{|c|c|c|c|c|c|c|c|c|}
\hline \multirow{2}{*}{ Variable } & \multicolumn{2}{|c|}{ Belgium } & \multicolumn{2}{|c|}{ France } & \multicolumn{2}{|c|}{ Germany } & \multicolumn{2}{|c|}{ The Netherlands } \\
\hline & Women & Men & Women & Men & Women & Men & Women & Men \\
\hline \multicolumn{9}{|c|}{ Period 2002-2006 } \\
\hline Intercept $\left(\alpha_{2}\right)$ & $86.6^{* * *}$ & $91.4^{* * *}$ & $89.2^{* * *}$ & $92.6^{* * *}$ & $89.9^{* * *}$ & $87.9^{* * *}$ & $89.4^{* * *}$ & $92.5^{* * *}$ \\
\hline \multicolumn{9}{|c|}{ Age (Ref: 45-49) } \\
\hline $50-54\left(\beta_{2,2}\right)$ & $-7.5^{* * *}$ & $-8.5^{* * *}$ & $-3.9^{* * *}$ & $-5.9^{* * *}$ & $-4.2^{* * *}$ & $-5.6^{* * *}$ & $-6.1^{* * *}$ & $-5.2^{* * *}$ \\
\hline $55-59\left(\beta_{3,2}\right)$ & $-29.3^{* * *}$ & $-36.0^{* * *}$ & $-22.5^{* * *}$ & $-36.9^{* * *}$ & $-16.5^{* * *}$ & $-18.3^{* * *}$ & $-22.3^{* * *}$ & $-24.1^{* * *}$ \\
\hline $60-64\left(\beta_{4,2}\right)$ & $-60.4^{* * *}$ & $-67.5^{* * *}$ & $-64.2^{* * *}$ & $-76.0^{* * *}$ & $-55.2^{* * *}$ & $-56.9^{* * *}$ & $-55.8^{* * *}$ & $-67.5^{* * *}$ \\
\hline \multicolumn{9}{|c|}{ Education (Ref: High) } \\
\hline $\operatorname{Medium}\left(\gamma_{2,2}\right)$ & $-11.1^{* * *}$ & $-11.0^{* * *}$ & $-7.3^{* * *}$ & $-13.6^{* * *}$ & $-12.9^{* * *}$ & $-14.3^{* * *}$ & $-9.8^{* * *}$ & $-7.1^{* * *}$ \\
\hline $\operatorname{Low}\left(\gamma_{3,2}\right)$ & $-28.1^{* * *}$ & $-26.5^{* * *}$ & $-17.3^{* * *}$ & $-22.3^{* * *}$ & $-24.4^{* * *}$ & $-25.1^{* * *}$ & $-25.2^{* * *}$ & $-13.1^{* * *}$ \\
\hline \multicolumn{9}{|c|}{ Country of birth (Ref: Country) } \\
\hline $\operatorname{Abroad}\left(\delta_{2,2}\right)$ & $-8.1^{* * *}$ & $-10.4^{* * *}$ & $-6.7^{* * *}$ & $-1.7^{* * *}$ & $-2.5^{* * *}$ & $-3.2^{* * *}$ & $-7.5^{* * *}$ & $-12.0^{* * *}$ \\
\hline \multicolumn{9}{|c|}{ Marital status (Ref. single) } \\
\hline Married $\left(\eta_{2,2}\right)$ & $-4.4^{* * *}$ & $+8.1^{* * *}$ & $-4.6^{* * *}$ & $+7.9^{* * *}$ & $-5.4^{* * *}$ & $+8.7^{* * *}$ & $-2.6^{* * *}$ & $+8.2^{* * *}$ \\
\hline Widow $\left(\eta_{3,2}\right)$ & $-1.9^{* * *}$ & $+3.2^{* * *}$ & $-1.4^{* * *}$ & $+2.8^{* * *}$ & $-2.1^{* * *}$ & $+1.7^{* * *}$ & -0.6 & $+1.5^{* * *}$ \\
\hline \multicolumn{9}{|c|}{ Period (Ref: 2002-2006) } \\
\hline $2007-2011\left(\tilde{\alpha}_{3}\right)$ & $+2.3^{* * *}$ & +0.4 & $+1.0^{* * *}$ & $+1.5^{* * *}$ & $+2.3^{* * *}$ & $+4.0^{* * *}$ & $+2.9^{* * *}$ & +0.7 \\
\hline \multicolumn{9}{|c|}{ Crossed effects (2007-2011) } \\
\hline \multicolumn{9}{|c|}{ Age (Ref: 45-49) } \\
\hline $50-54\left(\tilde{\beta}_{2,3}\right)$ & $+1.4^{* *}$ & $+2.4^{* * *}$ & $+1.0^{* * *}$ & $+2.0^{* * *}$ & +0.7 & -0.1 & $+1.6^{* * *}$ & +0.1 \\
\hline $55-59\left(\tilde{\beta}_{3,3}\right)$ & $+5.3^{* * *}$ & $+5.4^{* * *}$ & $+3.4^{* * *}$ & $+5.3^{* * *}$ & $+2.6^{* * *}$ & +0.4 & $+5.6^{* * *}$ & $+6.2^{* * *}$ \\
\hline $60-64\left(\tilde{\beta}_{4,3}\right)$ & $+2.6^{* * *}$ & $+1.3^{* *}$ & $+1.5^{* * *}$ & $+3.5^{* * *}$ & $+9.7^{* * *}$ & $+5.0^{* * *}$ & $+7.0^{* * *}$ & $+8.5^{* * *}$ \\
\hline \multicolumn{9}{|c|}{ Education (Ref: High) } \\
\hline $\operatorname{Medium}\left(\tilde{\gamma}_{2,3}\right)$ & +0.4 & -1.4 & $+0.7^{*}$ & $-1.4^{* *}$ & +0.1 & +0.2 & -0.1 & -0.1 \\
\hline $\operatorname{Low}\left(\tilde{\gamma}_{3,3}\right)$ & +0.1 & $-1.7^{*}$ & -0.7 & $-2.5^{* * *}$ & $-1.8^{*}$ & $-3.5^{* * *}$ & $-1.2^{*}$ & -0.8 \\
\hline \multicolumn{9}{|c|}{ Country of birth (Ref: Country) } \\
\hline $\operatorname{Abroad}\left(\tilde{\delta}_{2,3}\right)$ & $-1.2^{*}$ & +0.2 & $+0.7^{*}$ & +0.2 & $-2.4^{* * *}$ & $-2.2^{* * *}$ & $-2.1^{* * *}$ & $-2.3^{* *}$ \\
\hline \multicolumn{9}{|c|}{ Marital status (Ref. single) } \\
\hline $\operatorname{Married}\left(\tilde{\eta}_{2,3}\right)$ & +0.3 & +0.5 & +0.4 & $-0.7^{* * *}$ & $+1.8^{* *}$ & $+0.7^{* * *}$ & +0.7 & $+0.7^{* *}$ \\
\hline Widow $\left(\tilde{\eta}_{3,3}\right)$ & +0.5 & $+1.5^{* *}$ & $+1.1^{* *}$ & -0.1 & +1.1 & +0.5 & -0.9 & +1.0 \\
\hline \multicolumn{9}{|c|}{ Sample size } \\
\hline \# obs. (x 1000) & 121.4 & 115.3 & 432.4 & 402.5 & 233.0 & 227.0 & 203.6 & 201.7 \\
\hline
\end{tabular}

Notes: In italic, estimated employment probability in \% points for the reference category.

${ }^{* * *, * *, *}$ Statistically significant coefficients at $1 \%, 5 \%$ and $10 \%$ thresholds $\left(x^{2}\right.$ test) respectively (robust estimation). 
Table 5. Hours of work determinants by country and sex (in hours). Period 1997-2006.

Heckman two-step model. Estimated marginal effects in hours.

\begin{tabular}{|c|c|c|c|c|c|c|}
\hline \multirow{2}{*}{ Variable } & \multicolumn{2}{|c|}{ Belgium } & \multicolumn{2}{|c|}{ France } & \multicolumn{2}{|c|}{ The Netherlands } \\
\hline & Women & Men & Women & Men & Women & Men \\
\hline \multicolumn{7}{|c|}{ Period 1997-2001 } \\
\hline Intercept $\left(\alpha_{1}\right)$ & $28.9^{* * *}$ & $41.6^{* * *}$ & $31.7^{* * *}$ & $43.1^{* * *}$ & $26.5^{* * *}$ & $37.3^{* * *}$ \\
\hline \multicolumn{7}{|c|}{ Age (Ref: 45-49) } \\
\hline $50-54\left(\beta_{2,1}\right)$ & -0.26 & -0.02 & $-0.41^{* * *}$ & +0.12 & +0.21 & $-0.63^{* * *}$ \\
\hline $55-59\left(\beta_{3,1}\right)$ & +0.19 & $+1.38^{* * *}$ & $-1.91^{* * *}$ & -0.13 & -0.24 & $-1.89^{* * *}$ \\
\hline $60-64\left(\beta_{4,1}\right)$ & +0.18 & $+2.67^{* * *}$ & $-2.13^{* * *}$ & $+2.18^{* * *}$ & -0.42 & $-3.57^{* * *}$ \\
\hline \multicolumn{7}{|c|}{ Education (Ref: High) } \\
\hline $\operatorname{Medium}\left(\gamma_{2,1}\right)$ & $+3.04^{* * *}$ & -0.32 & $+1.57^{* * *}$ & $-0.52^{* * *}$ & $-1.09^{* * *}$ & $+1.22^{* * *}$ \\
\hline $\operatorname{Low}\left(\gamma_{2,1}\right)$ & $+2.08^{* * *}$ & $-0.60^{* *}$ & +0.10 & $-1.48^{* * *}$ & $-2.86^{* * *}$ & $+0.74^{* * *}$ \\
\hline \multicolumn{7}{|c|}{ Country of birth (Ref: Country) } \\
\hline Abroad $\left(\delta_{2,1}\right)$ & $+2.16^{* * *}$ & $+0.67^{* *}$ & $-0.82^{* * *}$ & $-1.22^{* * *}$ & $+3.23^{* * *}$ & $-0.64^{* * *}$ \\
\hline \multicolumn{7}{|c|}{ Other } \\
\hline Seniority $\left(\tau_{l}\right)$ & $+0.16^{* * *}$ & -0.01 & $+0.17^{* * *}$ & $-0.03^{* * *}$ & $+0.14^{* * *}$ & $+0.14^{* * *}$ \\
\hline \multicolumn{7}{|c|}{ Period (Ref: 1997-2001) } \\
\hline $2002-2006\left(\tilde{\alpha}_{2}\right)$ & $+1.88^{* * *}$ & +0.54 & $+2.07^{* * *}$ & $+2.54^{* * *}$ & +0.25 & $+0.44^{* *}$ \\
\hline \multicolumn{7}{|c|}{ Crossed effects (2002-2006) } \\
\hline \multicolumn{7}{|c|}{ Age (Ref: 45-49) } \\
\hline $50-54\left(\tilde{\beta}_{2,2}\right)$ & $-0.74^{* *}$ & $-0.66^{* *}$ & $+0.59^{* * *}$ & $+0.35^{* *}$ & +0.20 & -0.04 \\
\hline $55-59\left(\tilde{\beta}_{3,2}\right)$ & $-1.10^{* *}$ & $-1.89^{* * *}$ & $+1.17^{* * *}$ & $+1.57^{* * *}$ & $+0.59^{* *}$ & +0.04 \\
\hline $60-64\left(\tilde{\beta}_{4,2}\right)$ & +0.31 & $-2.74^{* * *}$ & $+1.44^{* * *}$ & +0.61 & $+2.20^{* * *}$ & +0.20 \\
\hline \multicolumn{7}{|c|}{ Education (Ref: High) } \\
\hline $\operatorname{Medium}\left(\tilde{\gamma}_{2,2}\right)$ & $-2.99^{* * *}$ & $-0.91^{* * *}$ & $-2.36^{* * *}$ & $-2.11^{* * *}$ & $-0.55^{* *}$ & +0.02 \\
\hline $\operatorname{Low}\left(\tilde{\gamma}_{3,2}\right)$ & $-3.68^{* * *}$ & $-1.89^{* * *}$ & $-2.06^{* * *}$ & $-2.90^{* * *}$ & $+0.66^{* * *}$ & +0.01 \\
\hline \multicolumn{7}{|c|}{ Country of birth (Ref: Country) } \\
\hline $\operatorname{Abroad}\left(\tilde{\delta}_{2,2}\right)$ & -0.29 & $-0.90^{* *}$ & +0.10 & -0.06 & -0.30 & $+0.49^{*}$ \\
\hline \multicolumn{7}{|c|}{ Other } \\
\hline Seniority $\left(\tilde{\tau}_{2}\right)$ & $-0.04^{* *}$ & $+0.04^{* * *}$ & $-0.04^{* * *}$ & $-0.03^{* * *}$ & $-0.02^{*}$ & $-0.05^{* * *}$ \\
\hline Mills ratio & $+2.56^{* * *}$ & $+2.43^{* * *}$ & $+2.48^{* * *}$ & $+2.42^{* * *}$ & $+2.31^{* * *}$ & $+2.28^{* * *}$ \\
\hline \multicolumn{7}{|c|}{ Sample size } \\
\hline \# obs. (x 1000) & 26.2 & 37.3 & 103.7 & 114.0 & 75.2 & 125.6 \\
\hline
\end{tabular}

Statistically significant at $1 \%, 5 \%$ and $10 \%$ thresholds $\left(\chi^{2}\right.$ test), robust estimation. 
Table 6. Hours of work determinants by country and sex. Period 2002-2011.

Heckman two-step model. Estimated marginal effects in hours.

\begin{tabular}{|c|c|c|c|c|c|c|c|c|}
\hline \multirow{2}{*}{ Variable } & \multicolumn{2}{|c|}{ Belgium } & \multicolumn{2}{|c|}{ France } & \multicolumn{2}{|c|}{ Germany } & \multicolumn{2}{|c|}{ The Netherlands } \\
\hline & Women & Men & Women & Men & Women & Men & Women & Men \\
\hline \multicolumn{9}{|c|}{ Period 2002-2006 (direct effects) } \\
\hline Intercept $\left(\alpha_{2}\right)$ & $30.7^{* * *}$ & $42.12^{* * *}$ & $33.7^{* * *}$ & $45.7^{* * *}$ & $31.7^{* * *}$ & $42.7^{* * *}$ & $26.7^{* * *}$ & $37.7^{* * *}$ \\
\hline \multicolumn{9}{|c|}{ Age (Ref: 45-49) } \\
\hline $50-54\left(\beta_{2,2}\right)$ & $-1.00^{* * *}$ & $-0.66^{* * *}$ & +0.15 & $+0.46^{* * *}$ & +0.11 & $-0.17^{* *}$ & $+0.37^{* * *}$ & $-0.66^{* * *}$ \\
\hline $55-59\left(\beta_{3,2}\right)$ & $-0.89^{* * *}$ & $-0.40^{*}$ & $-0.88^{* * *}$ & $+1.39^{* * *}$ & -0.10 & $-0.38^{* * *}$ & $+0.22^{* *}$ & $-1.84^{* * *}$ \\
\hline $60-64\left(\beta_{4,2}\right)$ & +0.53 & +0.19 & $-1.14^{* * *}$ & $+2.64^{* * *}$ & $-1.19^{* * *}$ & $-1.50^{* * *}$ & $+1.44^{* * *}$ & $-3.29^{* * *}$ \\
\hline \multicolumn{9}{|c|}{ Education (Ref: High) } \\
\hline $\operatorname{Medium}\left(\gamma_{2,2}\right)$ & +0.05 & $-1.20^{* * *}$ & $-0.84^{* * *}$ & $-2.65^{* * *}$ & $-2.88^{* * *}$ & $-2.45^{* * *}$ & $-1.70^{* * *}$ & $+1.24^{* * *}$ \\
\hline $\operatorname{Low}\left(\gamma_{3,2}\right)$ & $-1.58^{* * *}$ & $-2.41^{* * *}$ & $-2.07^{* * *}$ & $-4.41^{* * *}$ & $-4.37^{* * *}$ & $-2.75^{* * *}$ & $-2.35^{* * *}$ & $+1.00^{* * *}$ \\
\hline \multicolumn{9}{|c|}{ Country of birth (Ref: Country) } \\
\hline $\operatorname{Abroad}\left(\delta_{2,2}\right)$ & $+1.88^{* * *}$ & -0.19 & $-0.77^{* * *}$ & $-1.28^{* * *}$ & $+0.92^{* * *}$ & $-0.89^{* * *}$ & $+2.89^{* * *}$ & -0.15 \\
\hline \multicolumn{9}{|c|}{ Other } \\
\hline Seniority $\left(\tau_{2}\right)$ & $+0.12^{* * *}$ & $+0.03^{* * *}$ & $+0.13^{* * *}$ & $-0.05^{* * *}$ & $+0.23^{* * *}$ & $+0.05^{* * *}$ & $+0.12^{* * *}$ & $+0.08^{* * *}$ \\
\hline \multicolumn{9}{|c|}{ Period (Ref: 2002-2006) } \\
\hline 2007-2011 $\left(\tilde{\alpha}_{3}\right)$ & $+1.60^{* * *}$ & $+0.53^{* *}$ & $+0.83^{* * *}$ & $-0.49^{* * *}$ & -0.41 & +0.13 & +0.05 & $+0.24^{*}$ \\
\hline \multicolumn{9}{|c|}{ Crossed effects (2007-2011) } \\
\hline \multicolumn{9}{|c|}{ Age (Ref: 45-49) } \\
\hline $50-54\left(\tilde{\beta}_{2,3}\right)$ & -0.14 & -0.30 & $-0.62^{* * *}$ & $-0.46^{* * *}$ & -0.06 & $-0.41^{* *}$ & -0.20 & $-0.21^{*}$ \\
\hline $55-59\left(\tilde{\beta}_{3,3}\right)$ & $-0.67^{*}$ & $-1.15^{* * *}$ & $-0.46^{* * *}$ & $-1.19^{* * *}$ & -0.22 & $-0.90^{* * *}$ & $-0.51^{* * *}$ & $-0.57^{* * *}$ \\
\hline $60-64\left(\tilde{\beta}_{4,3}\right)$ & -1.21 & -0.61 & $-1.12^{* * *}$ & $-2.36^{* * *}$ & +0.54 & $-0.89^{* * *}$ & $-2.08^{* * *}$ & $-1.77^{* * *}$ \\
\hline \multicolumn{9}{|c|}{ Education (Ref: High) } \\
\hline $\operatorname{Medium}\left(\tilde{\gamma}_{2,3}\right)$ & $-1.64^{* * *}$ & $-0.80^{* * *}$ & $-0.90^{* * *}$ & $-0.27^{*}$ & $-1.08^{* * *}$ & $-0.28^{*}$ & $-0.76^{* * *}$ & -0.20 \\
\hline $\operatorname{Low}\left(\tilde{\gamma}_{3,3}\right)$ & $-1.74^{* * *}$ & $-0.47^{* *}$ & $-1.30^{* * *}$ & $-0.29^{* *}$ & $-0.59^{*}$ & $-1.76^{* * *}$ & $-0.97^{* * *}$ & -0.11 \\
\hline \multicolumn{9}{|c|}{ Country of birth (Ref: Country) } \\
\hline $\operatorname{Abroad}\left(\tilde{\delta}_{2,3}\right)$ & -0.21 & $+0.48^{*}$ & -0.09 & $+0.32^{* *}$ & $-0.73^{* *}$ & -0.04 & $+1.11^{* * *}$ & -0.03 \\
\hline \multicolumn{9}{|c|}{ Other } \\
\hline Seniority $\left(\tilde{\tau}_{3}\right)$ & $-0.02^{* *}$ & +0.01 & $+0.03^{* * *}$ & $+0.06^{* * *}$ & $+0.03^{* * *}$ & $+0.03^{* * *}$ & -0.00 & $+0.02^{* * *}$ \\
\hline Mills ratio & $+2.50^{* * *}$ & $+2.43^{* * *}$ & $+2.48^{* * *}$ & $+2.45^{* * *}$ & $+2.56^{* * *}$ & $+2.34^{* * *}$ & $+2.27^{* * *}$ & $+2.26^{* * *}$ \\
\hline \multicolumn{9}{|c|}{ Sample size } \\
\hline \# obs. (x 1000) & 51.7 & 64.1 & 111.6 & 120.0 & 127.8 & 155.2 & 101.2 & 151.5 \\
\hline
\end{tabular}

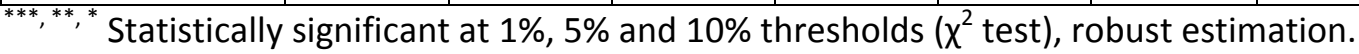


Table 7. Changes in total hours of work by country, age group and sex. Micro-simulation results based on estimated parameters.

\begin{tabular}{|c|c|c|c|c|c|c|}
\hline Country & Gender & $\begin{array}{c}\text { Demographic } \\
\text { Change } \\
\text { (a) }\end{array}$ & $\begin{array}{c}\text { Extensive } \\
\text { Change } \\
\text { (b) }\end{array}$ & $\begin{array}{l}\text { Intensive } \\
\text { Change } \\
\text { (c) }\end{array}$ & $\begin{array}{c}\text { Behavioral } \\
\text { Change } \\
\left(b^{*} c\right)\end{array}$ & $\begin{array}{c}\text { Total } \\
\text { Change } \\
(a * b * c)\end{array}$ \\
\hline \multicolumn{7}{|c|}{ 55-59 years old : $2002-2006$ vs. $1997-2001$} \\
\hline \multirow[t]{2}{*}{ Belgium } & Women & 1.31 & 1.23 & 0.92 & 1.14 & 1.49 \\
\hline & Men & 1.27 & 1.09 & 0.96 & 1.05 & 1.34 \\
\hline \multirow[t]{2}{*}{ France } & Women & 1.41 & 1.16 & 1.02 & 1.18 & 1.67 \\
\hline & Men & 1.36 & 1.06 & 1.04 & 1.10 & 1.49 \\
\hline \multirow[t]{2}{*}{ The Netherlands } & Women & 1.34 & 1.31 & 1.02 & 1.34 & 1.80 \\
\hline & Men & 1.28 & 1.15 & 0.98 & 1.13 & 1.44 \\
\hline \multicolumn{7}{|c|}{ 55-59 years old : 2011-2007 vs. 2001-2006 } \\
\hline \multirow[t]{2}{*}{ Belgium } & Women & 1.15 & 1.27 & 0.98 & 1.24 & 1.42 \\
\hline & Men & 1.10 & 1.10 & 0.98 & 1.08 & 1.19 \\
\hline \multirow[t]{2}{*}{ France } & Women & 1.15 & 1.12 & 1.00 & 1.13 & 1.30 \\
\hline & Men & 1.10 & 1.07 & 0.99 & 1.06 & 1.17 \\
\hline \multirow[t]{2}{*}{ The Netherlands } & Women & 1.06 & 1.21 & 0.97 & 1.17 & 1.24 \\
\hline & Men & 1.01 & 1.08 & 1.00 & 1.08 & 1.09 \\
\hline \multirow[t]{2}{*}{ Germany } & Women & 1.25 & 1.15 & 0.97 & 1.12 & 1.39 \\
\hline & Men & 1.16 & 1.10 & 0.99 & 1.08 & 1.25 \\
\hline \multicolumn{7}{|c|}{$60-64$ years old : $2002-2006$ vs. $1997-2001$} \\
\hline \multirow[t]{2}{*}{ Belgium } & Women & 1.08 & 1.46 & 0.96 & 1.41 & 1.52 \\
\hline & Men & 1.03 & 1.12 & 0.95 & 1.06 & 1.09 \\
\hline \multirow[t]{2}{*}{ France } & Women & 1.06 & 1.16 & 1.03 & 1.20 & 1.26 \\
\hline & Men & 1.06 & 1.27 & 1.02 & 1.29 & 1.37 \\
\hline \multirow[t]{2}{*}{ The Netherlands } & Women & 1.22 & 1.57 & 1.08 & 1.69 & 2.06 \\
\hline & Men & 1.18 & 1.30 & 0.99 & 1.28 & 1.51 \\
\hline \multicolumn{7}{|c|}{ 60-64 years old : $2011-2007$ vs. $2001-2006$} \\
\hline \multirow[t]{2}{*}{ Belgium } & Women & 1.38 & 1.35 & 0.96 & 1.29 & 1.77 \\
\hline & Men & 1.33 & 1.09 & 0.99 & 1.09 & 1.45 \\
\hline \multirow[t]{2}{*}{ France } & Women & 1.46 & 1.20 & 0.98 & 1.18 & 1.72 \\
\hline & Men & 1.42 & 1.29 & 0.96 & 1.24 & 1.76 \\
\hline \multirow[t]{2}{*}{ The Netherlands } & Women & 1.34 & 1.47 & 0.91 & 1.34 & 1.80 \\
\hline & Men & 1.29 & 1.40 & 0.97 & 1.35 & 1.74 \\
\hline \multirow[t]{2}{*}{ Germany } & Women & 0.93 & 1.64 & 0.99 & 1.63 & 1.52 \\
\hline & Men & 0.89 & 1.38 & 0.99 & 1.37 & 1.21 \\
\hline
\end{tabular}

Microsimulation based on estimates underlying Tables 3-6 
Table A.1. Differences in differences, 5-year age cohort pseudo panel.

Dependent variable: Employment rate variations by cohort from period to period.

\begin{tabular}{|c|c|c|c|c|c|c|}
\hline \multirow{2}{*}{$\begin{array}{l}\text { Periods and } \\
\text { age groups }\end{array}$} & \multicolumn{2}{|c|}{ Belgium } & \multicolumn{2}{|c|}{ France } & \multicolumn{2}{|c|}{ The Netherlands } \\
\hline & Women & Men & Women & Men & Women & Men \\
\hline Intercept $\left(\alpha_{1}\right)$ & -0.6 & $-1.8^{* *}$ & $+1.0^{* *}$ & $-0.2^{* *}$ & $+5.5^{* * *}$ & $-1.3^{* * *}$ \\
\hline \multicolumn{7}{|c|}{ Direct effects by period } \\
\hline $1997-2001^{\mathrm{a}}$ & (Ref) & (Ref) & (Ref) & (Ref) & - & - \\
\hline $2002-2006\left(\tilde{\alpha}_{2}\right)$ & +0.2 & -0.1 & $+2.4^{* * *}$ & 0.0 & (Ref) & (Ref) \\
\hline $2007-2011\left(\tilde{\alpha}_{3}\right)$ & +0.9 & +0.5 & $+2.8^{* * *}$ & -0.4 & $-2.9^{* * *}$ & -0.1 \\
\hline \multicolumn{7}{|c|}{ Direct effects by age } \\
\hline $45-49$ & (Ref) & (Ref) & (Ref) & (Ref) & (Ref) & (Ref) \\
\hline $50-54\left(\beta_{2,1}\right)$ & $-5.8^{* * *}$ & $-7.0^{* * *}$ & $-4.3^{* * *}$ & $-3.6^{* * *}$ & $-6.8^{* * *}$ & -1.1 \\
\hline $55-59\left(\beta_{3,1}\right)$ & $-10.8^{* * *}$ & $-24.7^{* * *}$ & $-20.5^{* * *}$ & $-28.0^{* * *}$ & $-12.2^{* * *}$ & $-9.9^{* * *}$ \\
\hline $60-64\left(\beta_{4,1}\right)$ & $-13.1^{* * *}$ & $-27.6^{* * *}$ & $-31.5^{* * *}$ & $-45.4^{* * *}$ & $-23.4^{* * *}$ & $-32.7^{* * *}$ \\
\hline \multicolumn{7}{|c|}{ Crossed effects by age, period 2002-2006 } \\
\hline $45-49$ & (Ref) & (Ref) & (Ref) & (Ref) & - & - \\
\hline $50-54\left(\tilde{\beta}_{2,2}\right)$ & -1.9 & +1.2 & -0.1 & +0.4 & - & - \\
\hline 55-59 $\left(\tilde{\beta}_{3,2}\right)$ & -3.4 & +3.0 & -0.6 & $+4.3^{* *}$ & - & - \\
\hline $60-64\left(\tilde{\beta}_{4,2}\right)$ & -2.0 & 0.0 & -1.2 & $+5.1^{* * *}$ & - & - \\
\hline \multicolumn{7}{|c|}{ Crossed effects by age, period $2007-2011^{b}$} \\
\hline $45-49$ & (Ref) & (Ref) & (Ref) & (Ref) & (Ref) & (Ref) \\
\hline $50-54\left(\tilde{\beta}_{2,3}\right)$ & -1.2 & $+3.4^{* * *}$ & -0.6 & +1.0 & $+2.5^{* * *}$ & +0.2 \\
\hline 55-59 $\left(\tilde{\beta}_{3,3}\right)$ & -2.5 & $+6.9^{* * *}$ & $+2.1^{*}$ & $+5.9^{* * *}$ & $+3.7^{* * *}$ & $+3.4^{* * *}$ \\
\hline $60-64\left(\tilde{\beta}_{4,3}\right)$ & $-4.3^{* *}$ & -0.5 & $-6.2^{* * *}$ & $+5.4^{* * *}$ & +0.8 & $+3.4^{* *}$ \\
\hline \# obs. & 1,058 & 1,055 & 1,007 & 1,004 & 790 & 787 \\
\hline $\mathrm{R}^{2}$ & 0.379 & 0.680 & 0.856 & 0.876 & 0.586 & 0.731 \\
\hline
\end{tabular}

Statistically significant at $1 \%, 5 \%$ and $10 \%\left(\chi^{2}\right.$ test).

${ }^{a}$ France 1998-2001. ${ }^{b}$ Crossed effects measured with respect to period 1997-2001 (Belgium), 1998-2001

(France) and 2002-2006 (Netherlands). 